\title{
Activated Carbons Derived from Date (Phoenix dactylifera) Seeds with Excellent Iodine Adsorption Properties
}

\author{
Aabhash Kumar Mallick, Abhimanyu Jha, Bhadra Prasad Pokharel \\ Rajeshwar Man Shrestha, Rinita Rajbhandari ${ }^{1}$ \\ Department of Applied Sciences, Pulchowk Campus, Institute of Engineering \\ Tribhuvan University, Kathmandu, Nepal \\ 1Corresponding author: joshirinita@yahoo.com
}

Received: Dec 15, $2018 \quad$ Revised: Feb 5, $2019 \quad$ Accepted: Feb 10, 2019

\begin{abstract}
Activated carbons were prepared from date seed powder by chemical activation method using potassium hydroxide $(\mathrm{KOH})$ as activating agent at different temperatures $\left(400,500,600\right.$ and $\left.700{ }^{\circ} \mathrm{C}\right)$. Date seed powder was impregnated with $\mathrm{KOH}(1: 1$ weight ratio) and carbonizations were carried out under a constant flow of nitrogen $(120 \mathrm{cc} / \mathrm{min})$ in a tubular furnace. The activated carbons thus obtained were characterized by powder X- Ray diffraction and Raman scattering. XRD patterns revealed amorphous carbon structure, which was further confirmed by the Raman scattering. Surface morphology of ACs was studied by scanning electron microscopy (SEM). Date seed derived activated carbons showed good iodine adsorption properties giving iodine number value of $850 \mathrm{mg} / \mathrm{g}$, which is much higher than the commercial activated carbons. Therefore, $\mathrm{KOH}$ activated date seed derived carbons would have potential in dye adsorption and waste water treatments.
\end{abstract}

Key words: Date seeds, activated carbon, $\mathrm{XRD}$, raman scattering, iodine number, $\mathrm{KOH}$

\section{Introduction}

Activated carbon is a porous material prepared from carbonaceous materials with simultaneous activation by chemical or physical methods $[13,14,15]$. Physical activation requires rather high temperature $\left(800-1100^{\circ} \mathrm{C}\right)$ treatment with a constant flow of steam, carbon dioxide, nitrogen or air $[7,19]$. While in chemical activation, the precursor material is mixed with certain dehydrating (activating) agents such as phosphoric acid $\left(\mathrm{H}_{3} \mathrm{PO}_{4}\right)$, potassium hydroxide $(\mathrm{KOH})$, sodium hydroxide $(\mathrm{NaOH})$, zinc chloride $\left(\mathrm{ZnCl}_{2}\right)$, sodium carbonate $\left(\mathrm{Na}_{2} \mathrm{CO}_{3}\right)[2,8,12]$ etc. Then, carbonization occurs at relatively lower temperatures compared to the physical activation temperature $[4,3,18$, $16,10]$. These activating agents induce important changes in the pyrolytic decomposition of the lignocellulosic materials promoting depolymerization and dehydration of constituent biopolymers. Chemical activation is preferential over physical activation for enhancing porosity at a low energy consumption. Maximum pores can be created by optimizing the synthetic conditions such as activation temperature, time, and proper selection of the activating agent and the impregnation ratio with a precursor $[17,9]$. Recently, there has been a wide realization of the importance of agricultural waste as a cheap and renewable precursor for the preparation of activated carbons. Not much information is available regarding the preparation of activated carbon from date stones 
using potassium hydroxide as an activating agent in existing literature. Date [Phoenix dactylifera] also known as date palm is grown in tropic region is a flowering plant species in palm family, Arecaceae, cultivated for its edible sweet fruit. Activated carbons prepared from date stones by chemical activation with zinc chloride [1] and phosphoric acid are reported [6, 5, 8,11]. Therefore, the activated carbons from date stones chemically activated with potassium hydroxide carbonized at different temperatures and characterization by Iodine number, Raman Spectroscopy, X-ray Diffraction (XRD) and Scanning Electron Microscope (SEM) images are presented. Thus prepared activated carbons with high surface area from date seeds would be potential use for the adsorption of dyes and waste water treatment technology.

\section{Experimental Details}

\subsection{Materials}

Date seeds were collected from local market of Lalitpur, Nepal. Potassium hydroxide (KOH) with purity $>98 \%$ was purchased from Quailigens, India. The nitrogen is of ultra high pure (UHP).

\subsection{Preparation of Activated Carbon(AC)}

The precursor, Date seeds were collected from local market of Lalitpur, Nepal. These seeds were washed several times with distilled water and dried at $110{ }^{\circ} \mathrm{C}$ for $24 \mathrm{hrs}$. The dried seeds were crushed and grinded in an electric grinder and sieved through $300 \mu \mathrm{m}$ sieve. The sieved date seed particles were mixed with $\mathrm{KOH}$ in 1:1 weight ratio and then place in horizontal furnace (Accumax,India) under nitrogen flow of $120 \mathrm{ml} / \mathrm{min}$, carbonized at different temperatures at $400,500,600$ and $700^{\circ} \mathrm{C}$ for 3 hours represented as D-4,D-5, D-6 and D-7. The activated carbons were then cooled to room temperature and washed several times with distilled water to remove remaining chemicals. Then the carbons were dried in an oven at $110^{\circ} \mathrm{C}$ for 24 hours, cooled and were sieved to get the activated carbons of upto106 $\mu \mathrm{m}$ for further study.

\subsection{X-Ray Diffraction (XRD) Measurements}

X-ray diffraction (XRD) measurements were carried out on Rigaku X-ray diffractometer, RINT, Japan and operated at $40 \mathrm{kV}$ and $40 \mathrm{~mA}$ with $\mathrm{Cu}-\mathrm{K} \alpha$ radiation at room temperature.

\subsection{Raman Scattering}

Raman Scattering measurements were performed on Jobin-Yvon T64000. The activated carbon is excited using green laser of $514.5 \mathrm{~nm}$ with $0.5 \mathrm{~mW}$ power. The sample for Raman scattering were prepared on clean silicon wafers.

\subsection{Scanning Electron Microscopy (SEM)}

SEM images of samples were taken to investigate the surface morphology of the activated carbon using SEM: U-8000, Hitachi Co. LTD. Japan. EM images were taken at 5-10 kv.

\subsection{Iodine Number}

Iodine number is the most commonly used parameter to characterize activated carbon .The adsorption of iodine solution is considered a simple and quick test for determining the surface area of activated carbons. It is a measure of micro pore ( 0 to $20 \mathrm{~A}$ or up to $2 \mathrm{~nm})$ content of the activated 
carbon by absorption of iodine from solution. The iodine number, defined as the amount of iodine adsorbed per gram of activated carbon at an equilibrium concentration was measured according to the procedure established by the American Society for Testing and Materials (ASTM 2006). 0.1 $\mathrm{g}$ of dry activated carbon was taken in clean and dried test tube and $5 \mathrm{ml}$ of $5 \% \mathrm{HCl}$ was added and boiled. Then $10 \mathrm{ml}$ of $0.1 \mathrm{~N}$ iodine solution was added and shaken for one minute and filtered. The filtrate was titrated against standard sodium thiosulphate using starch as an indicator. The concentration of iodine adsorbed by activated carbon was calculated as amount of iodine adsorbed in milligrams per gram.

The Iodine Number can be calculated as.

$$
\text { Iodine number }\left(\frac{\mathrm{mg}}{\mathrm{g}}\right)=\mathrm{C} \times \text { Conversion factor }
$$

where $\mathrm{C}$ is the difference between Blank Reading and Volume of hypo solution consumed by adsorption of hypo solution by activated carbon. The Conversion Factor is determined from the equation (2) as

$$
\text { Conversion factor }=\frac{\text { Equivalent weight of Iodine } \times \text { Normality of Iodine } \times 10}{\text { Weight of Activated carbon } \times \text { Blank reading }}
$$

\section{Results and Discussion}

\subsection{X-Ray Diffraction (XRD)}

Fig. 1 shows XRD patterns of activated carbons from date seeds particles prepared by activation with $\mathrm{KOH}$ at same mixing in $1: 1$ weight ratio carbonized at $400^{\circ} \mathrm{C}$ to $700^{\circ} \mathrm{C}$. From the $\mathrm{XRD}$ graph

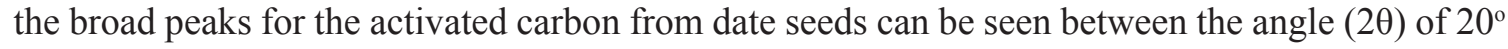
to $27^{\circ}$. In XRD pattern, appearance of broad peaks indicates the amorphous nature of the activated carbon and sharp peaks-crystalline nature [3]. This is the good property of activated carbon for the adsorption. The anomaly in the XRD graph as seen in the case of sample D-6, KOH activated carbon at $600^{\circ} \mathrm{C}$, is due to the presence of impurities [4]. This indicates that ACs contains only carbon materials with some oxygenated functional groups.

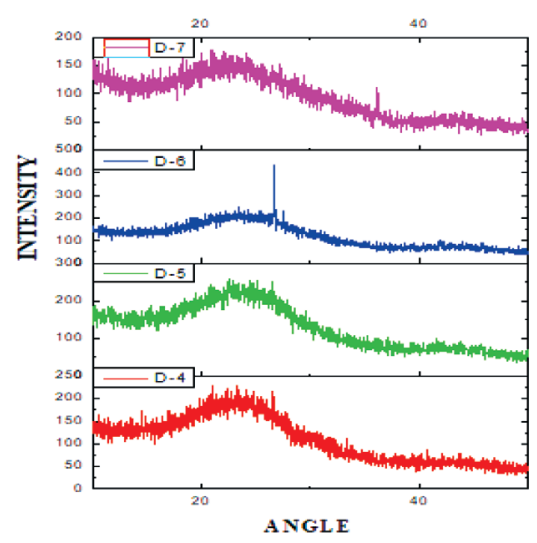

Fig. 1: XRD patterns of activated carbons derived from date seeds by $\mathrm{KOH}$ activation at different temperatures from $400^{\circ} \mathrm{C}$ to $700^{\circ} \mathrm{C}$ (D- 4), (D- 5),(D - 6), and (D - 7) 


\subsection{Raman Scattering}

Fig. 2 shows the Raman spectra of the prepared activated carbons from date seeds (D- 4), (D5), (D - 6) and (D - 7). The Raman spectra of all the samples exhibited strong D and G bands approximately at 1345 and $1588 \mathrm{~cm}^{-1}$, respectively. Usually, appearance of D band in Raman scattering is associated with a disordered carbon structure and the intensity of $\mathrm{D}$ band is correlated with the defects; D band intensity increases with the number of defects $[4,20]$. The $\mathrm{D}$ band is absent in single wall carbon nanotubes or pure graphitic carbon as these materials possess highly ordered carbon structure.

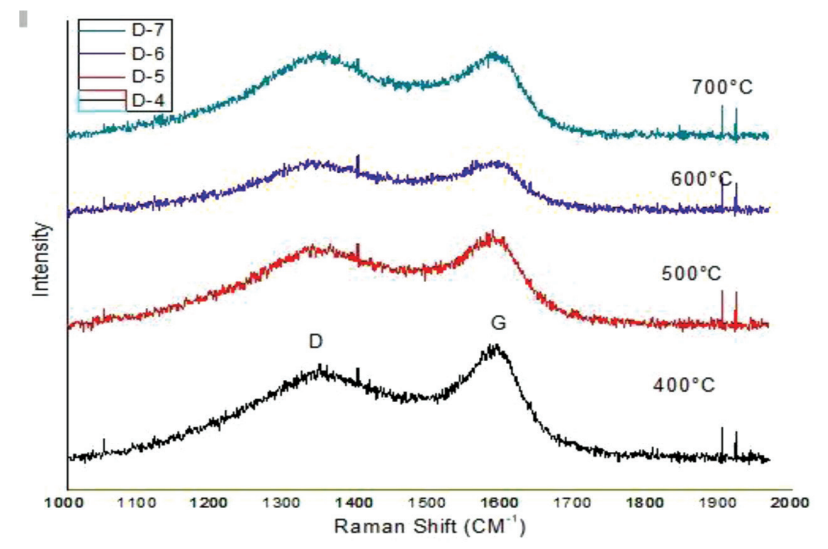

Fig. 2: Raman scattering patterns of activated carbons (D-4), (D-5), (D-6) and (D-7)

\subsection{Iodine Number}

Iodine Number determination for the activated carbon samples (D-4), (D- 5), (D - 6) and (D 7) results are given in Fig. 4. The figure clearly shows that with the increase in carbonization temperature from $400^{\circ} \mathrm{C}$ to $700^{\circ} \mathrm{C}$ the iodine number also increases gradually. This indicates that the activated carbon derived from date seeds chemically activated with potassium hydroxide with increase in carbonization temperature the microporosity also increases.

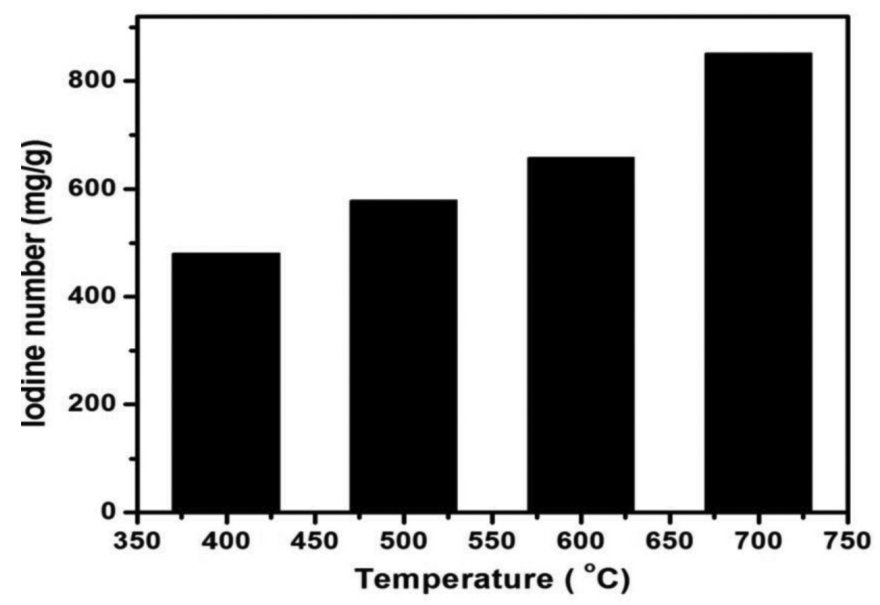

Fig. 3: Iodine Number of ACs prepared at different temperature 


\subsection{SEM Images of Activated Carbons}

Fig. 4 shows the surface morphology of the carbon sample carbonized at $700^{\circ} \mathrm{C}(\mathrm{D}-7)$. Observation of the images illustrates a large development of micro and mesopores. These micro and/or mesopores are responsible for the higher surface area of the material.

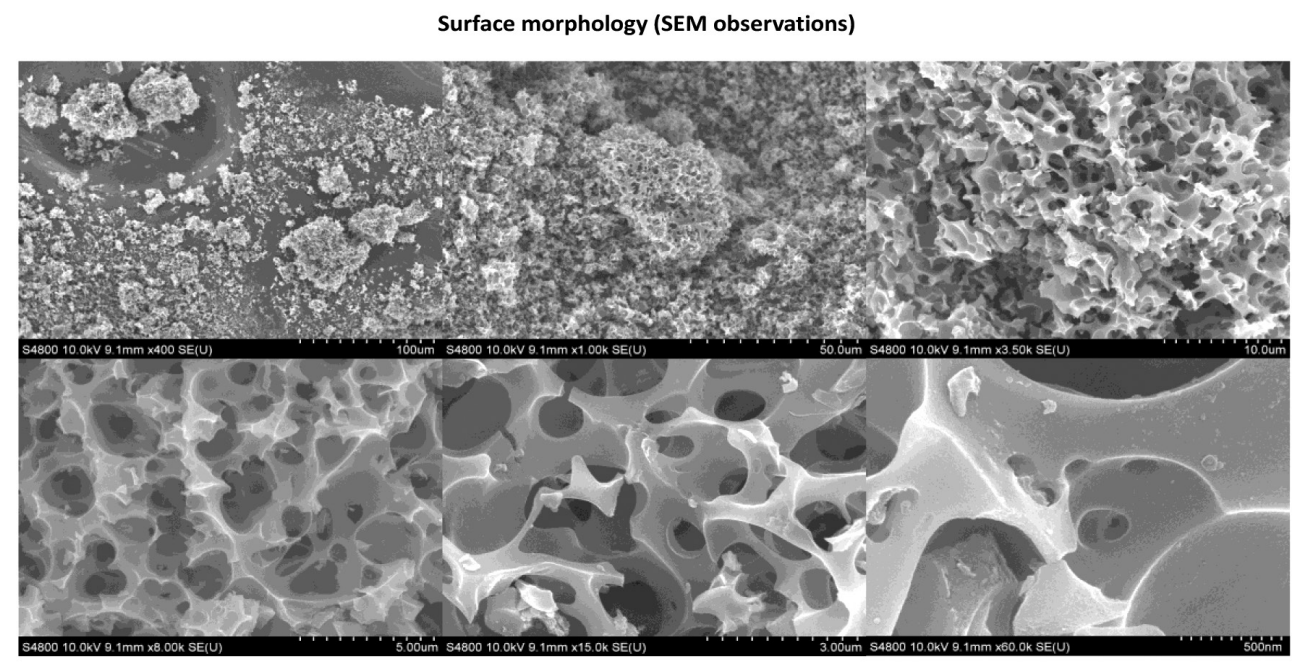

Fig. 4: SEM images of D-7

\section{Conclusion}

Activated carbons from date seed using potassium hydroxide as activating agent was successfully prepared. XRD pattern at different carbonization temperature of activated carbon indexed to amorphous in nature. For all sample Raman spectra exhibited strong D and G bands approximately at 1345 and $1588 \mathrm{~cm}^{-1}$ respectively. Iodine Number is highest for alkali activated carbonaceous material at $700^{\circ} \mathrm{C}$ indicating a high microporosity level. However the SEM images of D-7 seem to contain micro and mesopores. Thus prepared activated carbons with high surface area from date seeds would be use for the adsorption of dyes and waste water treatment technology.

Acknowledgment: The authors are thankful to Dr. Lok Kumar Shrestha from National Institute for Materials Science (NIMS), Japan, for scientific discussion and instrumental facilities (XRD, SEM and Raman scattering).

\section{References}

[1] Alhamed YA (2006), Activated Carbon from Dates Stone by $\mathrm{ZnCl}_{2}$ Activation, JKAU:Eng. Science, $75-100$.

[2] Akl et al. (2013), Removal of Iron and Manganese in Water Samples Using Activated, Chemical Engineering \& Process Technology, 4:4-10.

[3] Cazetta AL et al.(2011), $\mathrm{NaOH}$-activated carbon of high surface area produced from coconut shell: Kinetics and equilibrium studies from the methylene blue adsorption, Chem. Eng. J., 174:117-125.

[4] Elmouwahidi A et al. (2017), Activated carbons from $\mathrm{KOH}$ and $\mathrm{H}_{3} \mathrm{PO}_{4}$-activation of olive residues and its application as supercapacitor electrodes, Electrochim. Acta, 229: 219-228. 
[5] Fawzi B, Al-Asheh S and Al-Makhadmeh L (2003), Evaluation of the use of raw and activated date pits as potential adsorbents for dye containing waters, Process Biochemistry, 39: 193-202.

[6] Girgis, Badie S, El-Hendawy and Abdel-Nasser A (2002), Porosity development in activated carbons obtained from date pits under chemical activation with phosphoric acid, Microporous and Mesoporous Materials, 52: 105-117

[7] González JF et al., (2009), Porosity development in activated carbons prepard from walnut shells by carbon dioxide or steam activation, Ind. Eng. Chem. Res., 48: 7474-7481.

[8] Haimour NM and Emeish S (2005), Utillization of Dates stones for production of activated carbon using phosphoric acid, Waste Management, April (in press)

[9] Hameed BH (2009), Evaluation of papaya seeds as a novel non-conventional low-cost adsorbent for removal of methylene blue, J. Hazard. Mater., 162: 939-944.

[10] Hayashi J et al. (2002), Preparing activated carbons from various nutshells by chemical activation with $\mathrm{K}_{2} \mathrm{CO}_{3}$, Carbon, 40:2381-2386.

[11] Hussain FH et al. (2015), Preparation and Characterization of Activated Carbon from Iraqi Khestawy Date Palm, Journal of Chemistry, 2015:1- 8.

[12] Kang HY et al. (2006), Preparation of activated carbon from paper mill sludge by KOHactivation, Korean J. Chem. Eng, 23: 948-953.

[13] Lopez-Gonzalez JD, Martinez-Vilchez F and Rodriguez-Reinoso F (1980), Carbon 18, 413.

[14] Mohamed AR, Mohammadi M and Darzi GN (2010), Renewable and Sustainable Energy Reviews 14:1591-1599.

[15] Ncibia MC et al. (2009), Preparation and characterization of raw chars and physically activated carbons derived from marine Posidonia oceanic (L) fibres, J. Hazardous Materials, 165(1-2): 240-249.

[16] Okman I, Karagöz S, Tay T and Erdem M (2014), Activated carbon from grape seeds by chemical activation with potassium carbonate and potassium hydroxide, Appl. Surf. Sci., 293:138-142.

[17] Rafatullaha M, Sulaimana O, Hashima R and Ahmad A (2010), Adsorption of methylene blue on low-cost adsorbents: A review, J. Hazard. Mater. 177: 70-80.

[18] Rajbhandari R, Shrestha LK and Pradhananga RR (2012), Nanoporous activated carbon derived from Lapsi (Choerospondias Axillaris) seed stone for the removal of arsenic from water, $J$. Nanosci. Nanotechnol., 12: 7002-7009.

[19] Rodriguez-Reinoso F, Martin-Martinez JM, Molina-Sabio M, Perez-Lledo I and Pardo-Burguete (1985), Carbon 23, 19.

[20] Sisu C et al. (2016), Raman Spectroscopy Studies of Some Carbon Molecular Sieve, Digest Journal of Nanomaterials and Biostructures, 11(2): 435-442. 